\title{
Progestin increases the expression of gonadotropins in pituitaries of male zebrafish
}

\author{
Cuili Wang1,2, Dongteng Liu1,2, Weiting Chen3, Wei Ge3, Wanshu Hong1,2, Yong Zhu1,4 \\ and Shi $X$ Chen ${ }^{1,2,5}$ \\ 1State Key Laboratory of Marine Environmental Science, College of Ocean and Earth Sciences, Xiamen \\ University, Xiamen, China \\ ${ }^{2}$ Fujian Collaborative Innovation Center for Exploitation and Utilization of Marine Biological Resources, \\ Xiamen, China \\ ${ }^{3}$ Centre of Reproduction, Development and Aging (CRDA), Faculty of Health Sciences, University of \\ Macau, Taipa, Macau, China \\ 4Department of Biology, East Carolina University, Greenville, North Carolina, USA \\ ${ }^{5}$ State-Province Joint Engineering Laboratory of Marine Bioproducts and Technology, Xiamen University, \\ Xiamen, China
}

\author{
Correspondence \\ should be addressed \\ to $\mathrm{S} X$ Chen \\ Email \\ chenshixi@xmu.edu.cn
}

\begin{abstract}
Our previous study showed that the in vivo positive effects of $17 \alpha, 20 \beta$-dihydroxy-4pregnen-3-one (DHP), the major progestin in zebrafish, on early spermatogenesis was much stronger than the ex vivo ones, which may suggest an effect of DHP on the expression of gonadotropins. In our present study, we first observed that fshb and Ihb mRNA levels in the pituitary of male adult zebrafish were greatly inhibited by 3 weeks exposure to $10 \mathrm{nM}$ estradiol $\left(\mathrm{E}_{2}\right)$. However, an additional $24 \mathrm{~h} 100 \mathrm{nM}$ DHP exposure not only reversed the $\mathrm{E}_{2}$-induced inhibition, but also significantly increased the expression of fshb and Ihb mRNA. These stimulatory effects were also observed in male adult fish without $\mathrm{E}_{2}$ pretreatment, and a time course experiment showed that it took $24 \mathrm{~h}$ for $\mathrm{fsh} b$ and $12 \mathrm{~h}$ for $/ \mathrm{hb}$ to respond significantly. Because these stimulatory activities were partially antagonized by a nuclear progesterone receptor (Pgr) antagonist mifepristone, we generated a Pgr-knockout (pgr-l-) model using the TALEN technique. With and without DHP in vivo treatment, fshb and Ihb mRNA levels of $\mathrm{pgr}^{-1-}$ were significantly lower than those of $\mathrm{pgr}^{+/+}$. Furthermore, ex vivo treatment of pituitary fragments of $\mathrm{pgr}^{-1}$ with DHP stimulated $/ h b$, but not fshb mRNA expression. Results from doublecolored fluorescent in situ hybridization showed that pgr mRNA was expressed only in fshb-expressing cells. Taken together, our results indicated that DHP participated in the regulation of neuroendocrine control of reproduction in male zebrafish, and exerted a Pgr-mediated direct stimulatory effect on fshb mRNA at pituitary level.
\end{abstract}

\section{Key Words}

- 17 $\alpha, 20 \beta$-dihydroxy-4pregnen-3-one

- gonadotropin

- nuclear progesterone receptor

- zebrafish

- pituitary

\section{Introduction}

Gonadal steroid hormones play key roles in regulating gametogenesis, but they also exert both positive and negative feedback effects at the hypothalamic and pituitary levels. In tetrapod vertebrates, progesterone (P4) is the dominant ovarian progestin, which regulates reproductive behavior (Blaustein 1986) and exerts feedback effects on

Published by Bioscientifica Ltd
Journal of Endocrinology (2016) 230, 143-156 
both pituitary gonadotropin secretion (Turgeon \& Waring 1990, 2000, Waring \& Turgeon 1992) and hypothalamic gonadotropin-releasing hormone (GNRH) release (O'byrne

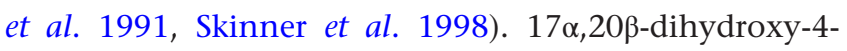
pregnen-3-one (DHP) and 17 $\alpha, 20 \beta, 21$-trihydroxy-pregn-

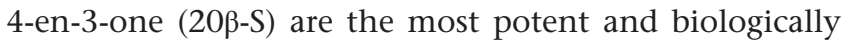
relevant progestins in teleosts (Scott et al. 2010). In male fish, progestins induce spermiation (Ueda et al. 1985), increase seminal fluid production (Baynes \& Scott 1985), and stimulate spermatozoa motility (Miura et al. 1992, Tubbs \& Thomas 2008). Studies in Japanese eel (Anguilla japonica) demonstrated that DHP induces the entry of male germ cells into meiosis (Miura et al. 2006). Our recent studies in zebrafish showed that DHP treatment increased proliferation and differentiation of early spermatogonial generation (Chen et al. 2013). Interestingly, the in vivo effect of DHP on spermatogonia was more prominent than that ex vivo. One likely mechanism is that the effects of DHP in vivo may involve both direct action at the testicular level and indirect modulation of pituitary gonadotropin release. Alternatively, in vitro incubation could also lead to dysregulation of many paracrine and autocrine signaling around testes that are important for DHP signaling.

In mammalian models, some studies reported no effect of progesterone on luteinizing hormone (LH) (Kerrigan et al. 1993, Park et al. 1996), while others using immortalized gonadotrope-derived L $\beta$ T2 cells (L beta T2 gonadotropecellline, Turgeonetal.1996)demonstrated that progesterone suppressed LH $\beta$ subunit gene expression, in contrast to its stimulatory effect on the expression of follicle-stimulating hormone (FSH) $\beta$ subunit (Thackray et al. 2006, 2009). In teleosts, much progress has been made in understanding the regulation of the GNRH-Fsh/Lh system by androgens and 17 $\beta$-estradiol (Zohar et al. 2010), but the potential roles of progestins in the neuroendocrine regulation of reproduction have received little attention. In female tilapia, DHP has been implicated in the regulation of Fsh and Lh release (Levavi-Sivan et al. 2006), but these DHP-mediated effects are considered to play a minor role in comparison to the dominant actions of androgen and $17 \beta$-estradiol (Van der Kraak 2009). Lack of information hinders an overall understanding of steroid hormones in regulating reproductive processes in teleosts.

The effects of progestins are mainly mediated through an intracellular nuclear progestin receptor (Pgr) that belongs to the nuclear receptor family (Conneely et al. 1986). In addition, multiple membrane progestin receptors (mPRs), which have no structural similarity to
Pgr, also can mediate the nonclassical action of progestin (Zhu et al. 2003, Hanna \& Zhu 2011, Tan \& Thomas 2015). In zebrafish, the Pgr is expressed robustly in the preoptic region of the hypothalamus (Hanna et al. 2010), and membrane progestin receptors (mPRs) in scattered cells in the pituitary (Hanna \& Zhu 2009), suggesting potential roles of progestins in the brain-pituitary complex and the involvement of multiple progestin receptors and signaling pathways.

Recently, we have clearly shown that Pgr knockout $\left(p g r^{-1-}\right)$ causes completely anovulation and infertility in female zebrafish, but male knockout fish is still fertile ( $\mathrm{Zhu}$ et al. 2015). In current study, we focused on the effects and molecular mechanisms of progestin (DHP) signaling in male zebrafish. We demonstrate that DHP can enhance the expression of gonadotropins ( $f s h b$ and $l h b$ transcripts) in the pituitaries of male adult zebrafish, independently of estradiol $\left(\mathrm{E}_{2}\right)$ inhibition. We also provide clear evidence from studies of Pgr antagonist, knockout and in situ to indicate that effects of progestin (DHP), especially, on $f s h b$ are mediated directly at least in part by Pgr that is expressed in Fsh-expressing cells in the pituitary of male zebrafish.

\section{Materials and methods}

\section{Zebrafish husbandry}

The experimental fish were Tübingen strain, which were housed in the zebrafish (Danio rerio) facility (ESSEN, China) and maintained in recirculating freshwater $(\mathrm{pH}$ 7.2-7.6) at $28^{\circ} \mathrm{C}$ with a $14 \mathrm{~L}: 10 \mathrm{D}$ photoperiod (lights on at $08: 00$ ). The fish were fed three times per day with commercial tropical fish food (Otohime B2, Reed Mariculture, Campbell, CA, USA), using standard conditions for this species (Westerfield 2000). All the fish used were mature adult males (age 4-6 months, body length $2.4-2.8 \mathrm{~cm}$, body weight $275-440 \mathrm{mg}$ ). Experimental protocols were approved by the Institutional Animal Care and Use Committee of Xiamen University.

\section{Generating and characterizing pgr $^{-1-}$ zebrafish using TALENs}

Instead of using an unit assembly protocol and a modified FokI (Huang et al. 2011, Zhu et al. 2015), we used a Golden Gate TALEN assembly protocol and wild type (WT) FokI (Cermak et al. 2011) to generate TALEN expression vectors targeting one locus as per the previous target (Zhu et al. 2015) located in the first exon (Fig. 1A) of the

Published by Bioscientifica Ltd. 
A

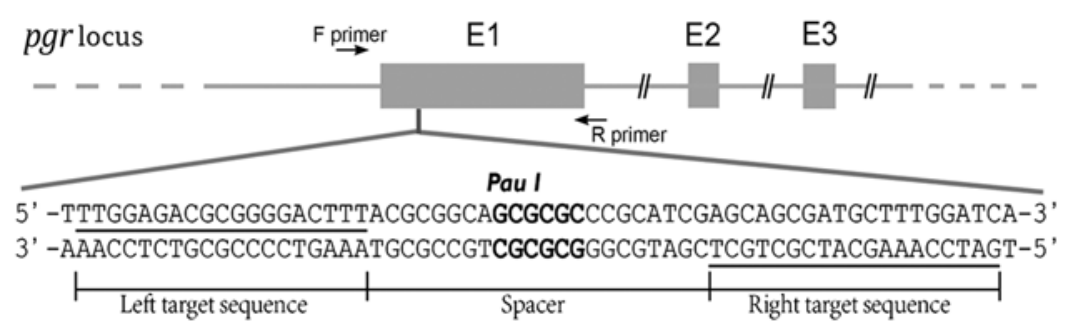

B

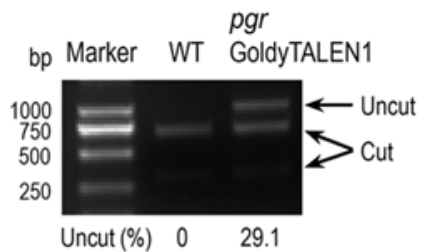

C

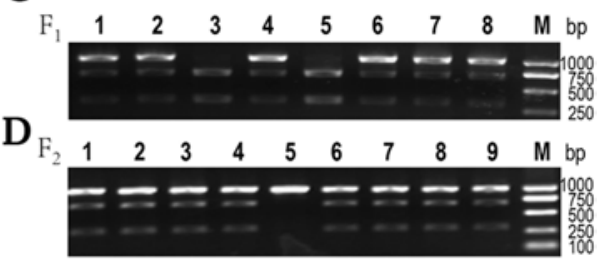

E $\begin{array}{lll}\text { TTTGGAGACGCGGGGACTTTACGCGGCAGCGCGCCCGCATCGAGCAGCGATGCTTTGGATCA } & \text { WT } \\ \text { TTTGGAGACGCGGGGACTTTACGCG-----GCCCGCATCGAGCAGCGATGCTTTGGATCA } & \Delta 7 \\ \text { TTTGGAGACGCGGGGACTTTACGCG--- } & \Delta 7\end{array}$

F

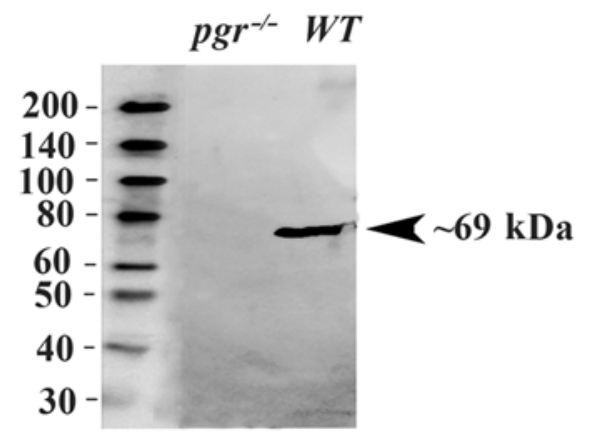

zebrafish pgr gene (Ensembl No. ENSDARG00000035966). Thereafter, assembled pgr GoldyTALEN expression vectors were linearized using SacI (Thermo Scientific), and transcribed into mRNAs using the Mmessage mMACHINE T3 Transcription Kit (Life Technologies).

Approximately $1 \mathrm{~nL}$ containing $75 \mathrm{pg}$ of each TALEN mRNA was injected into the yolk of each embryo at the one-cell stage. For examining the mutation rate of the injected embryos, a pool of genomic DNA was extracted from 30 injected embryos or the same number of WT embryos. With genomic DNA as template, a DNA fragment containing the TALEN target site was amplified using PCR (Fig. 1A and Table 1), followed by restriction endonuclease (PauI; Thermo Scientific) digestion, and checked with agarose gel electrophoresis. Area densities of cut and uncut bands on the gel were measured using the Gel-Pro Analyzer Program (Media Cybernetics, Rockville, MD, USA) (Fig. 1B), mutation efficiency being calculated as $(\%)=$ uncut $/($ cut + uncut $) \times 100 \%$.

\section{Figure 1}

Genomic structure of the rzebrafish pgr gene, TALEN targets, and a representative mutation induced by TALENs. (A) TALENs were designed to target the first exon of the pgr gene. The left and right binding sites of TALENs are underlined, and a restriction enzyme cleavage site with Paul used for mutation analysis is highlighted in bold. Forward and reverse primers for PCR amplification of the genomic fragment including the target region are also indicated by the arrow lines. (B) Mutation detection in injected FO founder embryos using Paul restriction enzyme digestion (mutation efficiency $29.1 \%$ ). (C) Genotype examination of $\mathrm{F} 1$ adult zebrafish using restriction enzyme digestion and tailfin clipping. Fish were individually numbered and are indicated on the top of the figure. No. 3 and 5 were wild-type fish, No. 1, 2, 4, 6, 7, and 8 were heterozygote fish. (D) Genotype examination of F2 adult zebrafish. Individual fish were numbered and are indicated on the top of the figure. No. 1, 2, 3, 4, 6, 7, 8, and 9 were heterozygote fish; No. 5 was a homozygote fish. (E) DNA sequences of wild type or Pgr mutant. Nucleotide deletion is indicated by dashed lines. The numbers at the right side show the number of deleted base pairs. (F) Western blot of the Pgr of zebrafish testes. Sample types are indicated on the top of the figure. $F$, forward; $\mathrm{R}$, reverse; No., number; WT, wild type; $\mathrm{pgr}^{-1}$, Pgr knockout.
To obtain homozygous mutant zebrafish, adult (>90 dpf) F0 founder fish were outcrossed with WT fish. From each cross, a pool of genomic DNA was extracted from 30 randomly selected F1 embryos, and the status of the TALEN target site was analyzed via PCR amplification, and restriction enzyme digestion as described above. Based on the mutation efficiency, the remaining F1 embryos from F0 founder fish with high rates of germline transmission were raised to adulthood and were genotyped individually using tail fin-clip screening assay in order to obtain heterozygous F1. Based on the DNA sequence of the TALEN target sites, heterozygous F1 fish with the same frame shift mutation were intercrossed to produce F2 offspring (Fig. 1C). Homozygous Pgr-knockout ( $\left.p g r^{--}\right)$, heterozygotes $\left(\mathrm{pgr}^{+-}\right)$) and homozygous wild type $\left(\mathrm{pgr}^{+/+}\right)$in F2 fish were identified via PCR amplification followed by restriction enzyme digestion analysis as described above (Fig. 1D).

In order to examine the $p g r$ mRNA sequence in $p g r^{-1-}$ male fish, cDNA was synthesized using a Revert Aid First

Published by Bioscientifica Ltd. 
Table 1 Primers used in present study.

\begin{tabular}{l} 
Primer name \\
\hline pgr-TALEN Forward \\
pgr-TALEN Reverse \\
pgr-Forward \\
pgr-Reverse \\
ef1a-Forward \\
ef1a-Reverse \\
fshb-Forward \\
fshb-Reverse \\
lhb-Forward \\
lhb-Reverse
\end{tabular}

\begin{tabular}{l} 
Primer sequence $\left.\mathbf{( 5}^{\prime} \mathbf{- 3} \mathbf{3}^{\mathbf{}}\right)$ \\
\hline AGGAATACGTCGCACACTTT \\
CGCCATTTTAATTCGACCTC \\
GGGTCTCGCTGCGTAATTTT \\
GCCTGGTAGCACTTTCGAAG \\
GGCTGACTGTGCTGTGCTGATTG \\
CTTGTCGGTGGGACGGCTAGG \\
CAGATGAGGATGCGTGTGC \\
ACCCCTGCAGGACAGCC \\
GCAGAGACACTTACAACAGCC \\
AAAACCAAGCTCTGAGCAGCC
\end{tabular}

$\frac{\text { Expected size }(\mathrm{bp})}{965}$

841

409

281

145

\begin{tabular}{l} 
GenBank accession number \\
\hline Ensembl No. \\
ENSDARG00000035966
\end{tabular}

Ensembl No. ENSDARG00000035966

BC064291

AY424303

AY424304/AY424305

\section{Purpose}

Positive gene Knockout fish screening

RT-PCR

Real-time PCR

Real-time PCR

Real-time PCR
Strand cDNA Synthesis Kit (Thermo Scientific) from the total RNA extracted from pooled pituitary samples using RNAzol reagent (MRC, Cincinnati, OH, USA). The specific PCR product was obtained using the Pgr-primers (Table 1), followed by cloning and Sanger sequencing.

In order to examine if Pgr protein was absent in $p g r^{-1-}$ male fish, testicular samples of WT and $\mathrm{pgr}^{-1-}$ fish were collected for western blot assay as described previously (Hanna et al. 2010). Total protein samples were extracted by immediately placing freshly excised testis into $1 \times$ SDS buffer, denatured by boiling for $5 \mathrm{~min}$, and then cooled on ice. Equal amounts $(60 \mu \mathrm{g})$ of protein samples were loaded and separated using a $12 \%$ SDS-PAGE gel and were transferred onto a PVDF membrane. The membrane was blocked in TBS containing $0.1 \%(\mathrm{v}: \mathrm{v})$ Tween 20 and 1\% (w:v) bovine serum albumin for $1 \mathrm{~h}$ at room temperature (RT), before the membrane was incubated with Pgr antibody (Hanna et al. 2010) for $24 \mathrm{~h}$ at $4^{\circ} \mathrm{C}$. After five washes with TBST, the membrane was incubated for $1 \mathrm{~h}$ at RT with the horseradish peroxidase (HRP)-conjugated secondary antibody (1:1000, v:v). A Bio-Rad ECL kit was used to detect signals on the PVDF membrane. Protein size was determined by comparing blotted protein size to a biotinylated protein ladder (Cell Signaling Technology, \#7727s) following the manufacturer's directions.

\section{Expression of $f s h b$ and Ihb mRNA during the diurnal cycle}

To examine the expression of $f s h b$ and $l h b$ mRNA levels in the pituitary during the diurnal cycle, mature WT male fish ( $>90 \mathrm{dpf}$ ) from the same batch were randomly chosen. Pituitary samples were collected every $4 \mathrm{~h}$ starting at 10:00 until 06:00. Since maximum levels were found at 06:00, expression levels of WT and $\mathrm{pgr}^{-1-}$ fish were compared at
06:00. Three pituitaries were pooled as one sample for these mRNA quantification studies.

\section{In vivo exposure to sex steroids}

Using a zebrafish model of estrogen-induced androgen insufficiency (De Waal et al. 2009), adult (>90 dpf) males were kept for 3 weeks in water containing $10 \mathrm{nM}$ estradiol $\left(\mathrm{E}_{2}\right)$ (Sigma-Aldrich). Fish were then exposed again to $10 \mathrm{nM} \mathrm{E}_{2}$ either with or without $100 \mathrm{nM}$ DHP (SigmaAldrich) for another $24 \mathrm{~h}$. From the same batch of male fish, animals without $\mathrm{E}_{2}$ pretreatment were exposed to $100 \mathrm{nM}$ DHP for $24 \mathrm{~h}$. Male fish were killed in ice water; pituitaries were collected (three pituitaries were pooled as one sample), frozen quickly in dry ice, and stored at $-80^{\circ} \mathrm{C}$ for RNA extraction.

For other in vivo exposure experiments, adult ( $>90 \mathrm{dpf}$ ) male fish were randomly divided into the control and DHP treatment groups. To determine an appropriate exposure concentration, fish were exposed to 10 or $100 \mathrm{nM}$ DHP for $24 \mathrm{~h}$ (starting at 13:00), while the control group was exposed to the vehicle (ethyl alcohol at a concentration of $0.0001 \%, \mathrm{v}: \mathrm{v})$. For time course experiments, treatment groups were exposed to $100 \mathrm{nM}$ DHP at 13:00, and pituitary samples were collected as described above at 16:00, 19:00, 01:00, and 13:00 to determine appropriate length of exposure time.

To study if the effects of DHP on $f s h b$ and $l h b$ transcript levels were Pgr-dependent, male fish were exposed to DHP (100 nM) and Pgr-specific antagonist (RU486, 0.1 or $1 \mu \mathrm{M})$ for $24 \mathrm{~h}$. An additional control group was exposed only to $1 \mu \mathrm{M} \mathrm{RU} 486$ for $24 \mathrm{~h}$. In addition, $\mathrm{pgr}^{-1-}$ male fish were exposed to the vehicle (as control, $0.0001 \%$ ethyl alcohol, v:v) or DHP $(100 \mathrm{nM})$ for a period of $24 \mathrm{~h}$. We also quantified the basal $f s h b$ and $l h b$ mRNA levels in $\mathrm{pgr}^{+/+}$fish.

Published by Bioscientifica Ltd. 


\section{Pituitary ex vivo exposure to sex steroids}

Pituitaries of mature male fish were removed, washed three times with Hank's balanced salt solution (without magnesium and calcium) in a 24-well plate (NEST, Rahway, NJ, USA), and then incubated individually in basal culture medium consisting of $15 \mathrm{mg} / \mathrm{mL}$ Leibovitz's L-15 medium (Invitrogen), supplemented with $10 \mathrm{mM}$ Hepes (Merck), $0.5 \%$ w/v BSA (MULT Sciences, China), 200U/mL penicillin, and $200 \mathrm{mg} / \mathrm{L}$ streptomycin (Invitrogen); $\mathrm{pH}$ was adjusted to 7.4 with $\mathrm{NaOH}$. Pituitary samples were incubated for $24 \mathrm{~h}$ in basal culture medium containing either $100 \mathrm{nM}$ DHP, or 0.0001\% (v:v) ethyl alcohol as control. Incubation was carried out in a humidified air atmosphere at $28^{\circ} \mathrm{C}$ for $24 \mathrm{~h}$, and three pituitaries were pooled to obtain one sample for gene expression analysis.

\section{Gene expression analysis}

Total RNA was extracted from pituitary samples using RNAzol reagent (MRC, Cincinnati, OH, USA). Three pituitaries were pooled as one sample to obtain sufficient RNA for cDNA synthesis. The same amount of total RNA $(1.0 \mu \mathrm{g})$ was used for the synthesis of the first-strand cDNAs using a Revert Aid First Strand cDNA Synthesis Kit (Thermo Scientific) following the manufacturer's instructions.

The relative expression levels of $f s h b, l h b$, and the house-keeping-gene efla were determined using realtime quantitative PCR (qPCR) with gene-specific primers (Table 1), which had been examined for their specificity and amplification efficiency on serial dilutions of respective target gene plasmid DNA $\left(2 \times 10^{2}-2 \times 10^{7}\right.$ copies $\left./ 2 \mu \mathrm{L}\right)$. qPCR was performed in a $20 \mu \mathrm{L}$ reaction mixture on the 7500 FAST real-time PCR detection system (Applied Biosystems) using default settings. Copies of ef $1 \alpha$, which showed no significant difference among different stages, were used as internal control. The relative mRNA levels of the target genes were determined using the comparative $C_{t}$ method (Schmittgen \& Livak 2008).

\section{Double-colored fluorescent in situ hybridization}

The colocalization of $p g r$ with either $f s h b$ or $l h b$ mRNA in zebrafish pituitary was investigated using double-colored fluorescent in situ hybridization (FISH), as described previously (Chen \& Ge 2012), except that cryosections were used. In brief, pituitaries of adult male zebrafish were dissected and fixed in $4 \% \mathrm{w} / \mathrm{v}$ paraformaldehyde in PBS at $4^{\circ} \mathrm{C}$ overnight, followed by immersion in $25 \% \mathrm{w} / \mathrm{v}$ sucrose in PBS at $4^{\circ} \mathrm{C}$ until sinking, and then embedded in optimal cutting compound (Tissue-Tek, Sakura, USA) by freezing in liquid nitrogen. Embedded pituitaries were processed for serial frozen sectioning at $10 \mu \mathrm{m}$ thickness, rehydrated and digested with proteinase $\mathrm{K}(5 \mu \mathrm{g} / \mathrm{mL}$; Roche Applied Science) at $37^{\circ} \mathrm{C}$ for $5 \mathrm{~min}$, followed by hybridization with fluorescein-labeled and DIG-labeled RNA probes at $55^{\circ} \mathrm{C}$ overnight. The probes for the detection of $f \mathrm{sh}, \operatorname{lhb}$ and pgr mRNA were generated as described previously (Chen et al. 2010, Chen \& Ge 2012). After hybridization, the cryosections were washed with $2 \times$ saline-sodium citrate (SSC; $0.06 \mathrm{M} \mathrm{NaCl}$ and $0.006 \mathrm{M}$ sodium citrate) for $30 \mathrm{~min}$ at RT, $30 \% \mathrm{v} / \mathrm{v}$ formamide deionized in $2 \times \mathrm{SSC}$ for $15 \mathrm{~min}$ at $65^{\circ} \mathrm{C}, 0.2 \times \mathrm{SSC}$ for $15 \mathrm{~min}$ at $65^{\circ} \mathrm{C}$, and $0.2 \times \mathrm{SSC}$ for $15 \mathrm{~min}$ at RT. After washing, a TSA Plus Cyanine3/ Fluorescein (TSA-Cy3) System (PerkinElmer) was used to detect the hybridization signal. The first signal was detected using HRP-conjugated anti-fluorescein antibody (Roche Applied Science) with TSA Fluorescein following the manufacturer's instructions. In order to detect the second signal, cryosections were incubated in $1 \% \mathrm{H}_{2} \mathrm{O}_{2}$ for $60 \mathrm{~min}$ to deactivate the HRP from the first staining. HRP-conjugated anti-DIG antibody (Roche Applied Science) were added to the sections, followed by detection with the TSA-Cy3 system. After mounting with the medium for fluorescence reagent (Vector Laboratories, Burlingame, CA, USA), the slides were observed and the images recorded using a Zeiss LSM 780 NLO two photon laser scanning system (Zeiss).

\section{Statistical analysis}

All data are presented as mean \pm s.e.m. of the mean. Depending on the experimental setup, data were analyzed using either Student's t-test or one-way ANOVA followed by Tukey's post hoc test to assess statistical differences between two or more groups. The analyses were performed using GraphPad Prism 4 software package (GraphPad Software).

\section{Results}

\section{Generating the $\mathrm{pgr}^{-1-}$ zebrafish model and knockout phenotype}

Mutant lines targeting two different loci with three different frame shift mutations caused by small deletions and/or insertions of nucleotides in the first exon of $p g r$ genomic sequences have been generated and characterized using a unit assembly protocol and modified FokI (for details, Zhu et al. 2015). In current study, we targeted same locus as one

Published by Bioscientifica Ltd 
of the previous targets (Fig. 1A) using a different TALEN assembly protocol and wild type FokI (Cermak et al. 2011), and successfully generated a new knockout line with a different frame shift (7-bp deletion) and a premature stop codon (Fig. 1B, C, D and E). Pgr protein was undetectable in the testes of $\mathrm{pgr}^{-1}$ - fish (Fig. 1F). We found exact same anovulation and infertility in newly generated knockout female zebrafish, which validated our previous finding (Zhu et al. 2015). Similarly, we found that Pgr knockout had no obvious effect in male fertility. So this new Pgr line was chosen for the following experiments.

\section{$E_{2}$ inhibited but DHP stimulated the expression of fshb and $/ h b$, independently from $E_{2}$ inhibition}

Both $f s h b$ and $l h b$ transcripts in the pituitaries of male zebrafish decreased significantly to 2 (fshb) or $20 \%$ (lhb) of the control after 3 weeks of $E_{2}$ (10 nM) exposure (Fig. 2). By contrast, expression of the $f s h b$ and $l h b$ transcripts in the pituitaries of male zebrafish increased significantly compared with the control when male fish were exposed to DHP both with or without $\mathrm{E}_{2}$ (Fig. 2).

\section{Dose and time-dependent stimulatory effects of progestin on the expression of $f s h b$ and $/ h b$}

Because pituitary $f s h b$ and $l h b$ transcript levels increased to similar levels in response to DHP irrespective of an $\mathrm{E}_{2}$ pretreatment, the subsequent DHP exposure experiments were carried out without $\mathrm{E}_{2}$ pretreatment.

Both $f s h b$ and $l h b$ transcripts in the pituitaries of male fish increased significantly (fivefold for $f s h b$, sevenfold for $l h b$ ) when fish were exposed to $100 \mathrm{nM}$ DHP water for $24 \mathrm{~h}$; while $10 \mathrm{nM}$ DHP exposure had no significant effects (Fig. 3A and B). The time course experiment indicated that significant increases of $f s h b$ and $l h b$ transcript levels in response to DHP $(100 \mathrm{nM})$ required at least $24 \mathrm{~h}$ and $12 \mathrm{~h}$ exposure, respectively (Fig. 3C and D).

\section{RU486 inhibited DHP-induced expression of fshb and $/ h b$ in the pituitary}

Effects of a Pgr-specific antagonist (RU486) were examined in order to determine if DHP-induced $f s h b$ and $\mathrm{lhb}$ expression was mediated through Pgr. RU486 alone, up to a concentration of $1 \mu \mathrm{M}$, did not alter fshb and $\mathrm{lhb}$ expression levels (Fig. 4), but RU486 significantly inhibited the stimulatory effects of DHP on the expression of $f s h b$ and $l h b$, in a dose-dependent manner (Fig. 4).
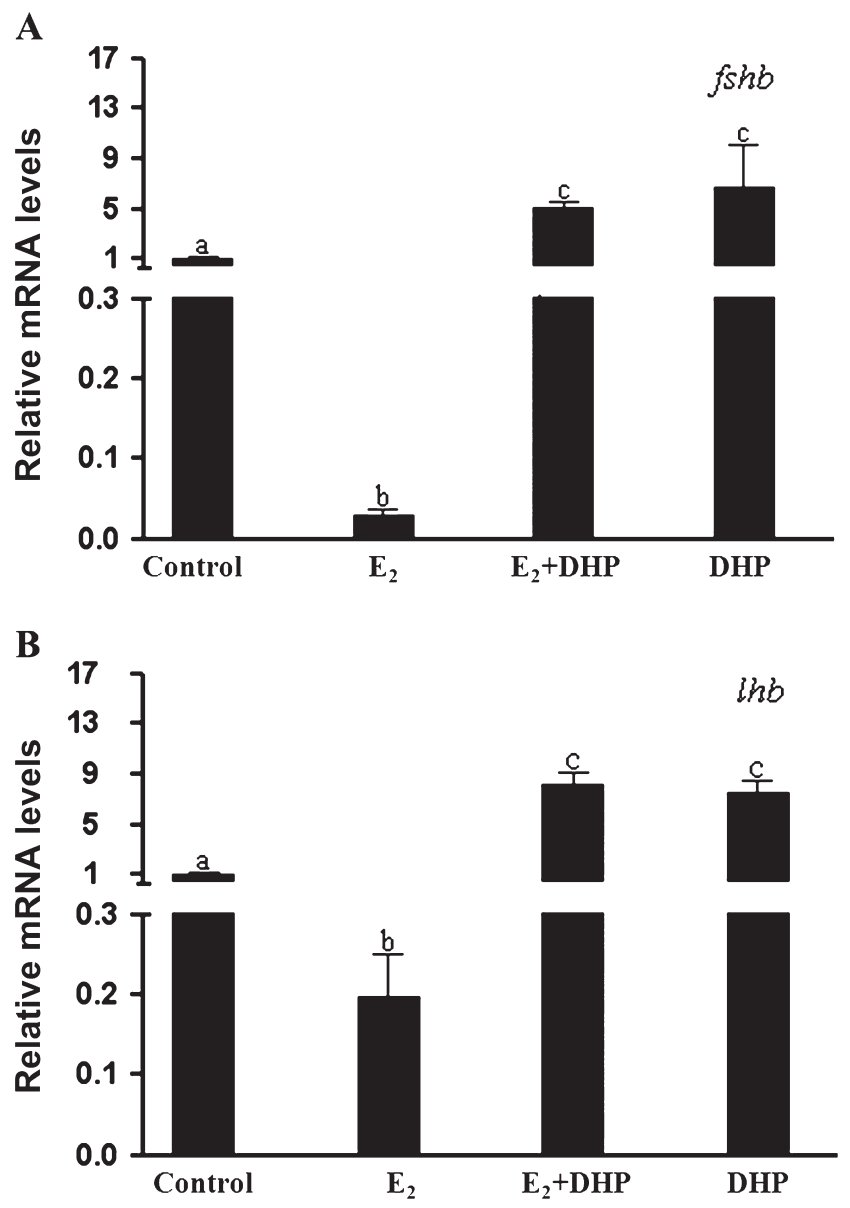

Figure 2

Effects of $E_{2}$ and DHP administration on fshb (A) and Ihb (B) mRNA levels in the pituitaries of wild-type male zebrafish. Zebrafish were maintained in the presence of $E_{2}(10 \mathrm{nM})$ alone for 3 weeks $\left(E_{2}\right)$ or in the additional presence of $100 \mathrm{nM}$ DHP during the last $24 \mathrm{~h}\left(E_{2}+\mathrm{DHP}\right)$ of the total 3-week-long exposure to $E_{2}$ in vivo. The same batch of male zebrafish without $E_{2}$ pretreatment were treated with DHP (100 nM) for $24 \mathrm{~h}$ in vivo. The levels of $f s h b$ and $I h b$ mRNA were determined using qPCR and normalized to the internal control gene (ef1a). Data are expressed as the mean \pm S.E.M. $(n=6)$ relative to the respective transcript levels of the control value. Mean values marked with different letters are significantly different from each other $(P<0.05)$.

\section{Daily expression levels of $f s h b$ and $/ h b$ transcripts in the pituitary of $\mathrm{pgr}^{-1-}$ male fish}

Expression of $f s h b$ and $l h b$ mRNA showed distinct diurnal changes in WT male fish. Both transcripts of $f s h b$ and $l h b$ were low in the late morning (10:00) after spawning and in the afternoon (14:00). The levels increased in the evening (18:00) and reached peak levels in early morning (06:00), $2 \mathrm{~h}$ before the lights came on and the start of spawning activity (Fig. 5A and B). The highest transcript level of $f s h b$ was $\sim 7.5$-fold higher than the lowest one, while that of $l h b$ was $\sim 4$.0-fold higher than the lowest one.

Published by Bioscientifica Ltd 

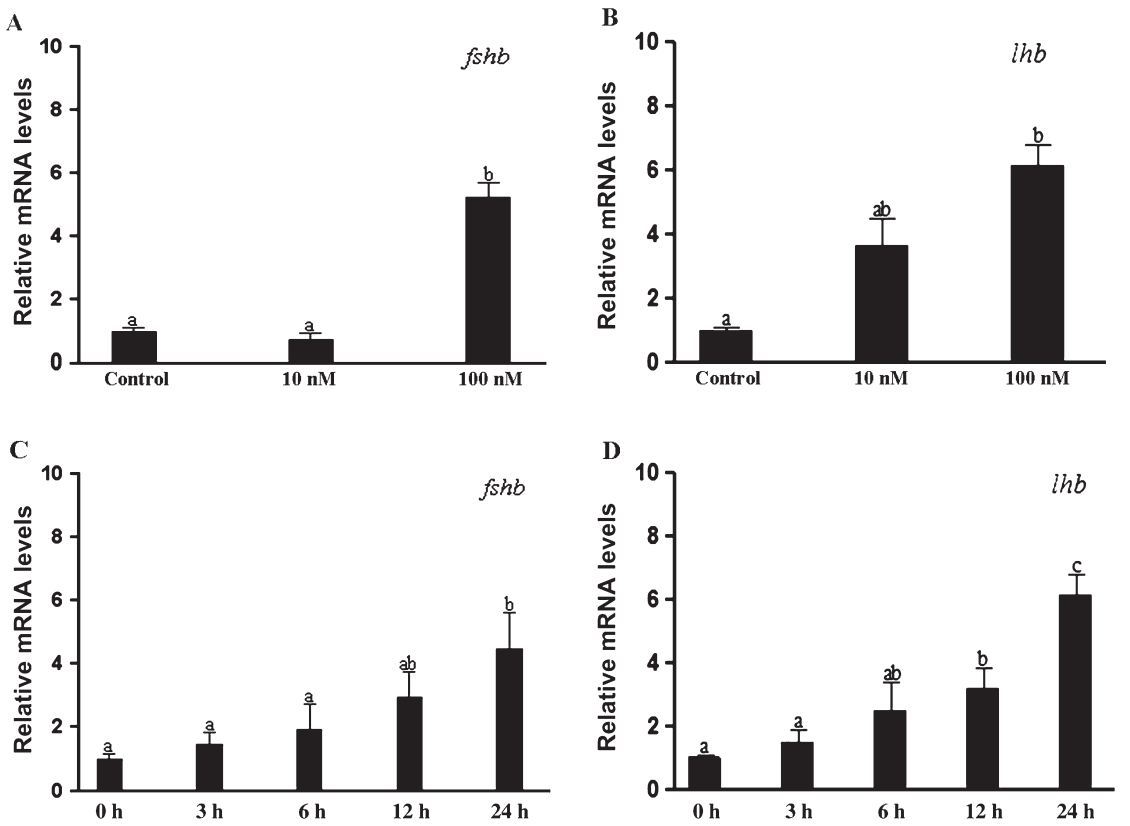

Figure 3
Dose- $(A$ and $B$ ) and time (C and D)-dependent
stimulation of progestin on the expression of $f$ shb
and Ihb transcripts in the pituitaries of wild-type
male zebrafish in vivo. Male zebrafish were
treated with DHP (10 or $100 \mathrm{nM}$ ) for $24 \mathrm{~h}$
(13:00-13:00 next day) in vivo (panels A and B).
Thereafter, based on the dose-response
experiment, an optimal dose level (100 nM) was
selected in the time course experiment (panels C
and D). Transcript levels of fshb or $/ h b$ at time
zero without progestin exposure are defined as
one, and data (mean \pm s.E.M., $n=6)$ are expressed
as fold changes to the zero value. Mean values
marked with different letters are significantly
different from each other $(P<0.05)$.

Furthermore, we observed that there was no difference in $f$ shb or $l h b$ transcript levels between control WT male (i.e., not treated with TALENs) and $\mathrm{pgr}^{+/+}$male pituitaries collected at 06:00 (Fig. 5C and D). This excluded potential TALEN induced off-target effects on the site that might affect the reproductive system. In addition, the levels of $f s h b$ and $l h b$ mRNA of $p g r^{-1}$ male fish were significantly lower than those of WT and $\mathrm{pgr}^{+/+}$collected at 06:00 (Fig. 5C and D).

\section{Effects of DHP on the expression of $f s h b$ and $/ h b$ in pgr $^{-1-}$ male zebrafish}

Surprisingly, we found that DHP still significantly increased the mRNA levels of $f$ shb and $l h b$ in $p^{-1-}$ - fish, but the magnitudes of the increases were significantly lower than those observed in WT fish (Fig. 6A and B).

To examine whether DHP acts directly at the pituitary level to increase $f s h b$ and $l h b$ mRNA levels, an ex vivo pituitary culture system was used. Both $f s h b$ and $\operatorname{lh} b$ transcripts increased significantly ( 2-fold for $f s h b, \sim 2.5$-fold for $\ln b$ ) in the cultured pituitary tissue fragments of both WT and $\mathrm{pgr}^{+/+}$males exposed to $100 \mathrm{nM}$ DHP for $24 \mathrm{~h}$ (Fig. 7). Furthermore, compared with the $\mathrm{pgr}^{-/}$- control, there was a significant increase ( twofold) of $l \mathrm{hb}$ transcript levels in pituitary fragments of $\mathrm{pgr}^{-1}$ - fish following exposure to $100 \mathrm{nM}$ DHP for $24 \mathrm{~h}$ (Fig. 7B), while $f$ shb transcript levels no longer responded to DHP in pituitaries of $\mathrm{pgr}^{-1-}$ males (Fig. 7A).

\section{pgr mRNA were expressed in fshb-expressing cells but not in $/ h b$-expressing cells}

Because the above results suggested that at least some part of DHP effects on gonadotropin hormone (GTH) expression were likely mediated by $p g r$, we further investigated if $p g r$ mRNA was expressed in gonadotropin cells for a direct action of DHP. Using double-colored FISH, which could detect the expression of two genes in the same section as reported previously (Chen \& Ge 2012), we observed that the fshb-expressing cells scattered individually in the pituitary, whereas the $\operatorname{lhb}$ expressing cells normally formed aggregates (Fig. 8A), which is consistent with a recent report (Golan et al. 2016). Because the expression level of $p g r$ mRNA was much lower than those of $f s h b$ and $l h b$ mRNA in the pituitary, the FISH signals of $p g r$ mRNA were observed only in a few cells scattered individually (Fig. 8B, C, D, $\mathrm{E}$ and $\mathrm{F}$ ). The FISH signal of $p g r$ transcript was mostly observed in $f$ shb-expressing cells (Fig. 8C, D, E and F), but none in $l h b$-expressing cells (Fig. $8 \mathrm{~B}$ ).

\section{Discussion}

Gonadal steroids exert negative or positive feedbacks on gonadotropin synthesis and secretion in various vertebrates. In the present study, we investigated the potential roles of DHP in regulating gonadotropin transcription in adult male zebrafish using morphological, physiological, and molecular approaches. The results

Published by Bioscientifica Ltd. 
A

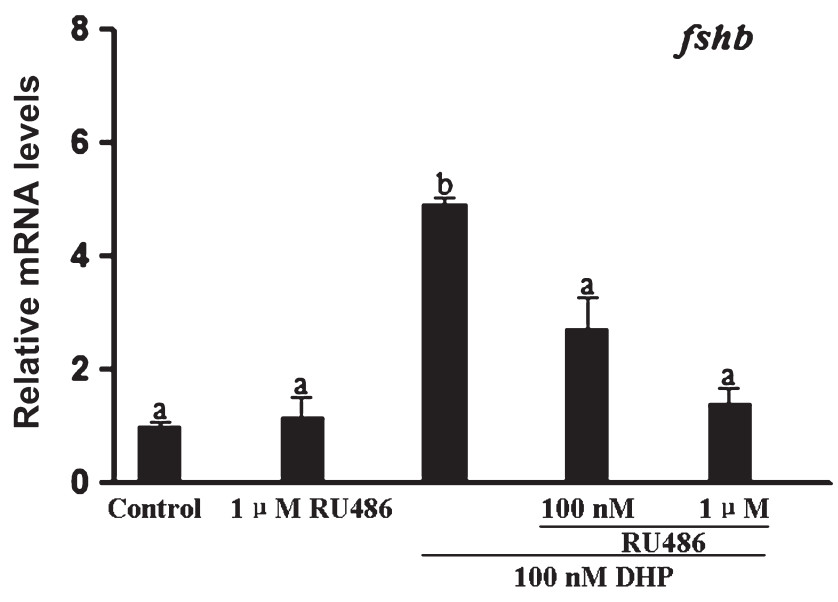

B

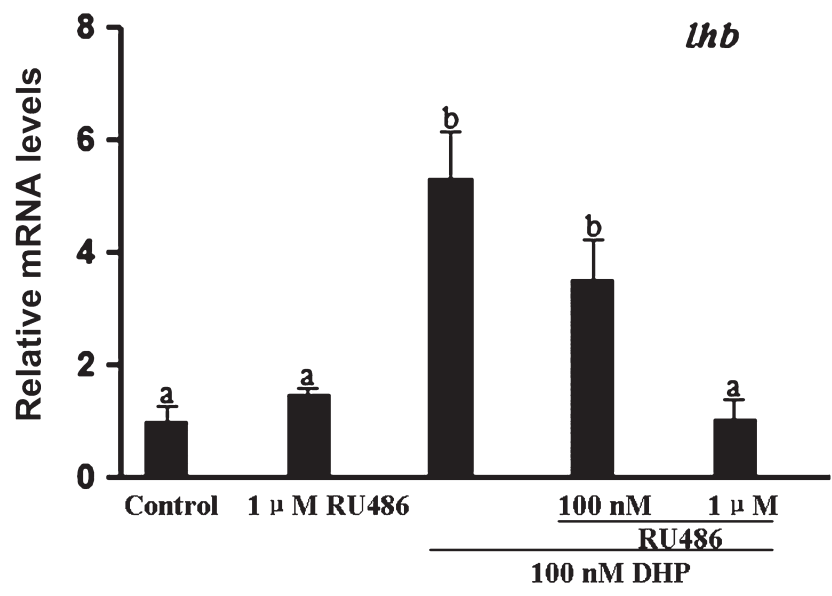

Figure 4

Effects of RU486 on DHP-stimulated $f s h b$ and $/ h b$ transcript expression levels of the wild-type (WT) male zebrafish. Data are expressed as the mean \pm S.E.M. $(n=6)$ relative to the respective transcript levels of the WT control ( $A$ and $B)$. Mean values marked with different letters are significantly different from each other $(P<0.05)$.

showed that DHP was able to stimulate the transcription levels of both $f s h b$ and $l h b$. Importantly, using $p g r^{-1-}$ fish, we demonstrated that the stimulatory effect of DHP on $f s h b$ mRNA was mediated by the Pgr which was expressed in $f$ shb-expressing pituitary cells.

We first applied the long-term $\mathrm{E}_{2}$ treatment model to examine the effects of DHP on gonadotropin subunit expression in vivo. Our results showed that DHP significantly increased gonadotropin subunit mRNA expression in the presence and absence of $\mathrm{E}_{2}$. This was different from that in mammalian models, in which many studies have shown that progesterone can suppress $L H$ mRNA levels in the presence of estrogen (Abbot et al. 1988, Simard et al. 1988, Corbani et al. 1990). Therefore, it seemed that there was no interaction between DHP and $\mathrm{E}_{2}$ in regulating GTH subunit expression in male zebrafish.

Extensive studies in goldfish have demonstrated that waterborne DHP is a pheromone which can increase LH, steroid, and seminal fluid production (Stacey \& Sorensen 1986, Dulka et al. 1987, Kobayashi et al. 2002). Because of the exposure via water in the present study, it is possible that DHP exerted its stimulatory effects as a pheromone. While the zebrafish ovary can produce steroid glucuronides, including 17,20 $\beta$-P-glucuronide, which are attractive to males, $17,20 \beta$-P-glucuronide has never been tested as a sex pheromone in male zebrafish. However, $17,20 \beta$-P-sulfate is the only steroid that males appear to be able to smell (Belanger et al. 2010). Sex pheromones usually induce a rapid endocrine response at low concentrations (pM and low nM). For example, exposure of goldfish to $0.5 \mathrm{nM}$ DHP increases serum LH levels after only $15 \mathrm{~min}$ (Dulka et al. 1987). However, in the present study, the significant response of $f s h b$ and $l \mathrm{hb}$ to DHP exposure required $24 \mathrm{~h}$ and $12 \mathrm{~h}$, respectively, reaching maximum levels after $24 \mathrm{~h}$ exposure, and DHP induced the upregulation of $f s h b$ mRNA expression only at a high concentration $(100 \mathrm{nM})$. Moreover, using the primary pituitary ex vivo culture system, we observed a stimulatory effect of DHP on GTH expression. Taken together, it was most likely that DHP induced GTH upregulation, especially $f s h b$ mRNA expression, through an endocrine pathway.

Several studies in fish report that plasma LH levels are very low during the early spermatogenesis stage and become detectable when germ cells entered meiosis; however, the increase is not prominent until the spawning season (Schulz et al. 2010). Similarly, the highest levels of circulating progestins are observed during the entire spermiation process, especially during the spawning season (Schulz et al. 2010). One physiological mechanism to explain this coincidence is that LH induced the production of DHP (Schulz et al. 2010). Our previous study in zebrafish also demonstrates that recombinant zebrafish Lh induces DHP production ex vivo (Chen et al. 2010). Data from the present study showed that DHP had a positive feedback on $l h b$ mRNA expression, which was in agreement with previous studies in female tilapia (Levavi-Sivan et al. 2006). These results might indicate that $\mathrm{LH}$ is the main factor regulating the production of the maturation-inducing hormone DHP.

An increase of $f s h b$ mRNA levels during spermiation is recorded in several teleost species, which may be due to environmental factors (i.e., temperature and photoperiod) (Schulz et al. 2010). In the present study, we report

Published by Bioscientifica Ltd 
A

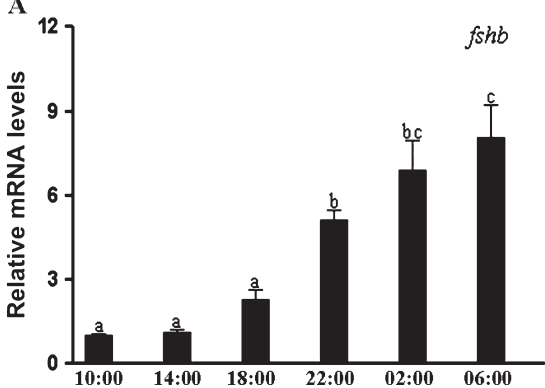

C

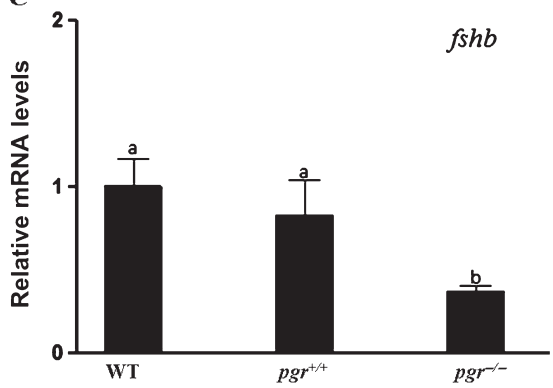

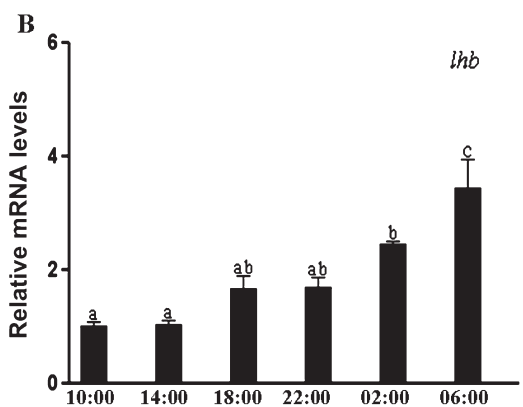

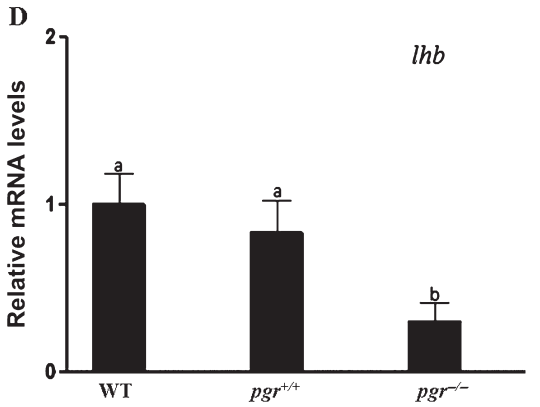

Figure 5

Diurnal changes of fshb (A) and Ihb (B) transcripts in the pituitaries of the wild-type (WT) male zebrafish, and the levels of fshb (C) and $/ h b(D)$ in the pituitaries of the WT, $\mathrm{pgr}^{+/+}$, and $\mathrm{pgr}^{-1-}$ male zebrafish collected at 06:00. Data are expressed as the mean \pm S.E.M. $(n=6)$ relative to the respective transcript levels at 10:00 (A and B) or WT (C and $D)$. Mean values marked with different letters are significantly different from each other $(P<0.05)$. that DHP increased $f s h b$ mRNA levels in male zebrafish. It is worth noting that this stimulatory effect required a high concentration of DHP (100 nM), which is supposed to happen during spawning. Therefore, we examined the diurnal changes of $f s h b$ expression levels, and the results indicated that both $f s h b$ and $l h b$ transcripts reached peak levels at 06:00, $2 \mathrm{~h}$ before spawning. Interestingly, a previous study in female zebrafish also reports an obvious elevation of $f s h b$ expression at 01:00 and 04:00 before final oocyte maturation at 07:00 (So et al. 2005). Taken together, these results suggested that FSH may be involved in final gamete maturation, which is different from the current view that FSH in fish is involved in early gametogenesis, that is, promoting the early stage of spermatogenesis in the testis, and stimulating follicle growth or vitellogenesis in the ovary. As a continuous daily breeder with an asynchronous spermatogenic cyst, it is most likely that zebrafish initiate the early stages of spermatogenesis at some point of time every day. Results from our present study supported the suggestion from our previous study that DHP-induced early spermatogenesis is mainly mediated by triggering the release of gonadotropins (Chen et al. 2013). Recent studies in zebrafish indicate that FSH promotion of proliferation and differentiation of spermatogonia does not require androgen, but can also be mediated by suppressing an inhibitor of spermatogenesis (Skaar et al. 2011), or by inducing a stimulator of spermatogenesis (Igf3) (Nóbrega et al. 2015). Moreover, the testes in fshr-lmales showed significant retardation in growth with delayed spermatogenesis and gonad formation, though male fertility did not seem to be affected (Zhang et al. $2015 a$ ). In contrast to significant effects and infertility due to $l h$-knockout in female fish, male fertility was also apparently not affected in zebrafish (Chu et al. 2014, Zhang et al. 2015b). However, our present study clearly indicates expressions of $f s h b$ and $l h b$ mRNA are regulated by feedback signaling of progestin in zebrafish. Taken together, FSH, LH, and progestin are working in concert to appropriately regulate gonadal growth, puberty onset, daily recruitment, and maturation of germ cells in male zebrafish. Clearly, additional studies are required to understand effects, regulation, and conserved functions of $\mathrm{LH}, \mathrm{FSH}$, progestin, and their receptors during reproduction and evolution.

Three classes of progestin receptors (Pgr, mPR, and progesterone receptor membrane component (Pgrmc)) are reported in vertebrates (Thomas 2008, Zhu et al. 2008). Previous reports and the present results showed that both Pgr and mPR are expressed in the zebrafish hypothalamus and pituitary (Hanna \& Zhu 2009, Chen et al. 2010, Hanna et al. 2010), so that DHP may induce GTH expression via Pgr or/and mPRs. The results from present study showed that the Pgr antagonist RU486 partially blocked the stimulatory effects of DHP. Furthermore, using a pituitary ex vivo culture system, we did not observe any stimulatory effect of DHP on $f s h b$ expression in the $\mathrm{pgr}^{-1-}$ model. Moreover, results from double-colored FISH showed that most of the FISH signals revealed by the $p g r$ probe were observed in $f$ shb-expressing cells, but not

Published by Bioscientifica Ltd. 
A

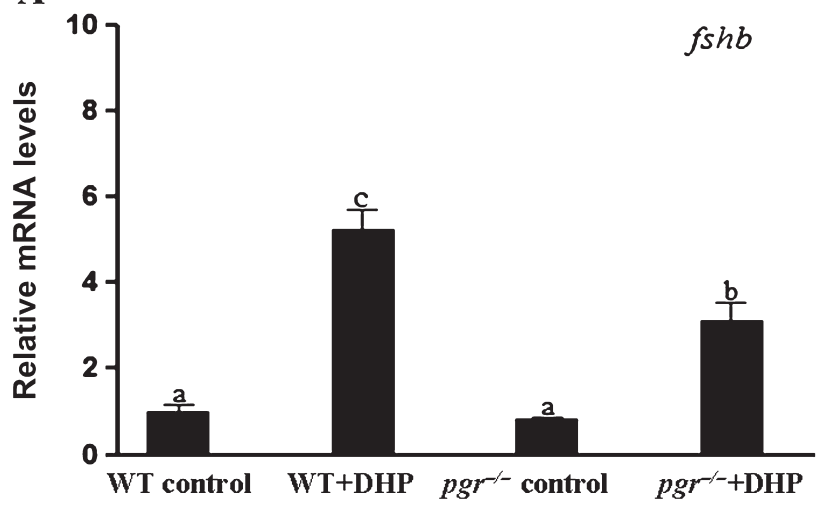

B

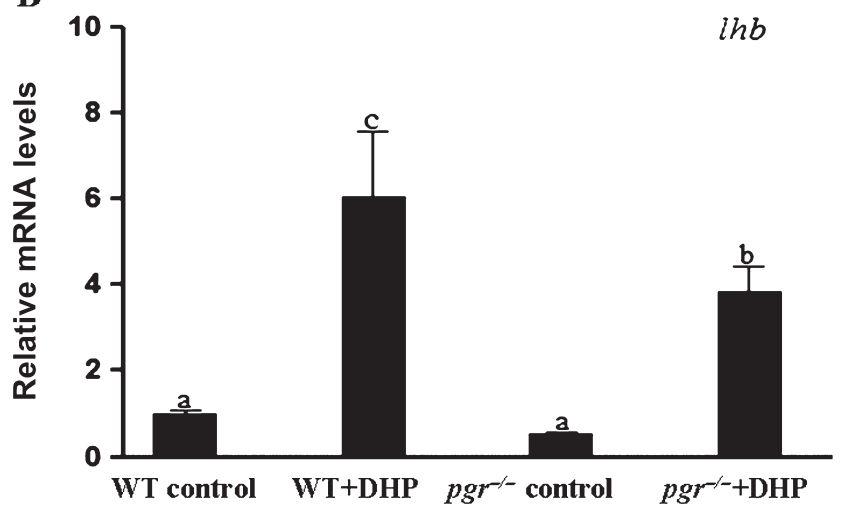

Figure 6

Stimulatory effects of DHP in the expression of $f s h b(A)$ and $/ h b$ (B) transcripts in the pituitaries were significantly blocked in $\mathrm{pgr}^{-1-}$ male zebrafish. Wild type (WT + DHP group) and pgr-1- (pgr-1- + DHP group) male zebrafish were treated with (100 nM) DHP for $24 \mathrm{~h}$ (13:00-13:00 next day). Wild-type control (WT control) and $\mathrm{pgr}^{-1}$ control groups were treated with the vehicle $(0.0001 \%)$ for $24 \mathrm{~h}$ (13:00-13:00 next day). The levels of $f s h b$ and Ihb mRNA were determined using qPCR and normalized to the internal control gene (ef1a). Transcript levels of fshb and $/ \mathrm{hb}$ obtained at the WT control are defined as one, and data (mean \pm S.E.M., $n=6$ ) are expressed as fold changes to the WT control. Mean values marked with different letters are significantly different from each other $(P<0.05)$.

in $l h b$-expressing cells. Our results clearly indicated that DHP exerted a direct stimulatory effect on $f s h b$ mRNA expression which was mediated by Pgr at the pituitary level. In mammals, it has been demonstrated that the full suppressive effect of progesterone on $L h b$ gene expression requires the unique amino-terminal region of the Pgr, but this suppression does not require direct binding of Pgr to the Lhb promoter although it is recruited to the endogenous promoter in live cells (Thackray et al. 2009). By contrast, progesterone directly activates Fshb through binding of Pgr in the proximal FSH promoter (Thackray et al. 2006). The molecular mechanism of progestins on $f s h b$ gene expression is conserved in vertebrates during
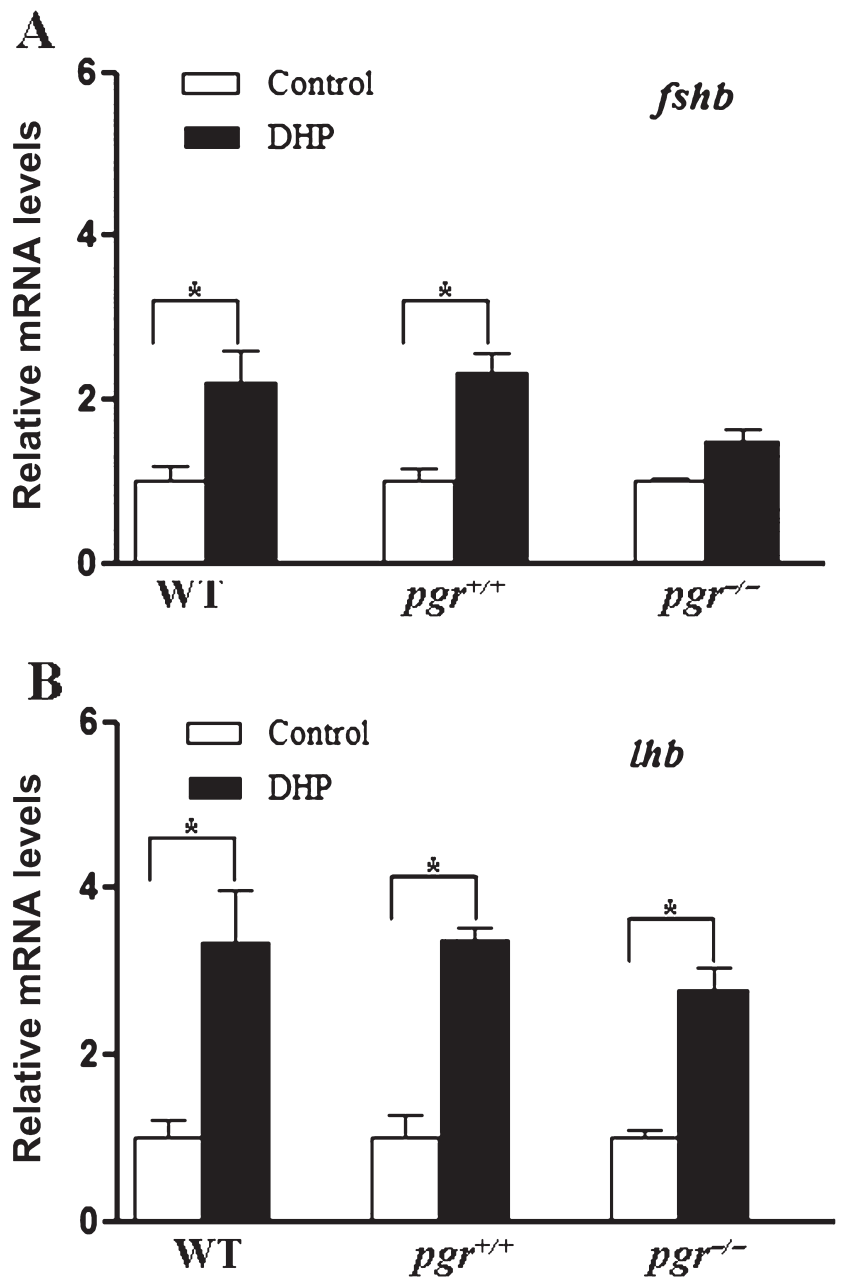

Figure 7

Ex vivo effects of DHP administration on $f$ shb (A) and lhb (B) mRNA levels. Pituitary fragments of wild type (WT), $\mathrm{pgr}^{+1+}$, and $\mathrm{pgr}^{-1-}$ male zebrafish were treated with $100 \mathrm{nM}$ DHP for $24 \mathrm{~h}$ (13:00-13:00 next day). WT, $\mathrm{pgr}^{+/+}$, and $\mathrm{pgr}^{-1-}$ controls were treated with the vehicle $(0.0001 \%)$ for 24h (13:00-13:00 next day). The levels of $f s h b$ and $/ h b$ mRNA were determined using qPCR and normalized to the internal control gene (ef1a). Transcript levels of fshb or lhb obtained at the WT control are defined as one, and data are expressed as the mean \pm s.E.M. $(n=6)$ relative to the respective transcript levels of the WT control value. Bars marked with * are significantly different from their respective controls $(P<0.05)$.

evolution. Further study is necessary to show whether other progestin receptors are involved in mediating the stimulatory effect of DHP on $l h b$ gene expression in fish.

Interestingly, DHP still caused upregulation of GTH expression in vivo in $p g r--$ male fish, suggesting that nonnuclear receptor mediated pathways in other brain regions, most likely in the hypothalamus, might be involved in the stimulatory effects of DHP on GTH. However, the relevant information is less documented in teleosts. In mammals, the molecular mechanisms of progesterone on GNRH were also unambiguous. Classic Pgr (Skinner et al. 1998), 

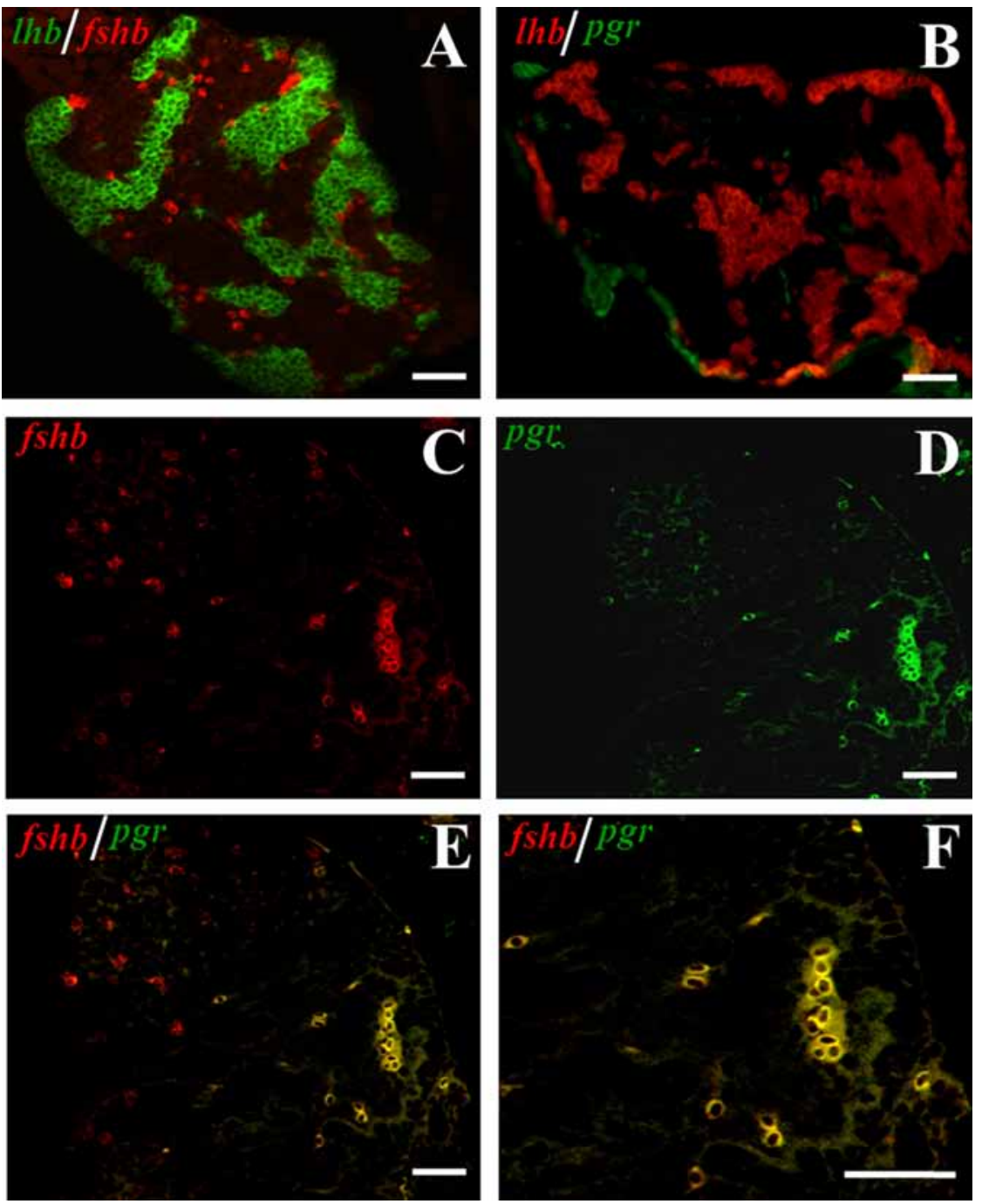

Figure 8

pgr mRNAs were expressed in fshb-expressing cells but not in Ihb-expressing cells. (A)

Cryosection stained for fshb (red) and Ihb (green); (B) Cryosection stained for $/ \mathrm{hb}$ (red) and pgr (green); ( $C$ and D) Cryosection stained for fshb (red) and pgr (green); and (E and F) Cryosection stained for $f s h b$ (red) and pgr (green); scale bars $=50 \mu \mathrm{M}$. A full colour version of this figure is available at http://dx.doi.org/10.1530/JOE-16-0073.

PAQR (Sleiter et al. 2009) and PGRMC1 (Bashour \& Wray 2012) are suggested as the key players in mediating progesterone action on GNRH. Further research is needed to address the involvement of other progestin receptors in mediating this effect.

In teleost fish, estrogenic compounds can inhibit androgen synthesis and prevent spermatogenesis (Van der Ven et al. 2003, 2007, Pawlowski et al. 2004, Van den Belt et al. 2004), but the mechanisms remain unclear. A study in zebrafish suggests that in vivo exposure to $\mathrm{E}_{2}$ causes a state of androgen insufficiency, involving feedback mechanisms on the hypothalamus-pituitary system (De Waal et al. 2009). In the present study, we observed in vivo a clear inhibitory effect of $\mathrm{E}_{2}$ on $f s h b$ and $l h b$ mRNA levels, similar to what is described in the closely related goldfish (Kobayashi et al. 2000, Huggard-Nelson et al. 2002). However, direct estrogenic stimulation of pituitary cells elevates $f s h b$ and $l h b$ transcript levels in zebrafish (Lin \& Ge 2009). Therefore, we concluded that in zebrafish, long-term exposure to $\mathrm{E}_{2}$ inhibited stimulatory or strengthened inhibitory signaling toward the pituitary gonadotropin cells, and these effects overruled the direct, stimulatory effects of $\mathrm{E}_{2}$ on gonadotropin subunit expression.

In summary, the present study indicated that DHP played an important role in the regulation of gonadotropin production in the male zebrafish pituitary. It is likely that the effect of DHP on gonadotropin gene expression may have resulted from integration of multiple effectors acting on the hypothalamus, as well as the pituitary. In addition, Pgr was the main but not the only receptor type for mediating this effect. However, at the pituitary level, DHP exerted a Pgr-mediated direct stimulatory effect on $f s h b$ mRNA. Despite this, $p g r^{-/-}$male fish are fertile (Zhu et al. 2015), which is similar to a mice model (Schneider et al. 2005), and the biological

Published by Bioscientifica Ltd 
significance of this stimulatory effect of DHP on gonadotropin gene expression remains to be clarified.

\section{Declaration of interest}

The authors declare that there is no conflict of interest that could be perceived as prejudicing the impartiality of the research reported.

\section{Funding}

This study was supported by the National Natural Science Foundation of China (No. 31201977 \& No. 41276129), the funding for Doctor Station of the Ministry of Education of China (No. 20120121110029), Xiamen Southern Oceanographic Center (No. 14GZY019NF19), and NIH 1R15GM100461-01A1.

\section{Author contribution statement}

$C L W$ was involved in entire study. D T L performed TALEN synthesizing, mutation screen. W T C performed double-colored fluorescent in situ hybridization. W G, Y Z, and W S H supervised the project and prepared manuscript drafting. $S \times C$ conceived and supervised the project, analyzed results, and wrote the paper.

\section{Acknowledgments}

The authors would like to express our great appreciation to Professor John Hodgkiss for assistance with the English.

\section{References}

Abbot SD, Docherty K \& Clayton RN 1988 Regulation of LH subunit mRNA levels by gonadal hormones in female rats. Journal of Molecular Endocrinology 1 49-60. (doi:10.1677/jme.0.0010049)

Bashour NM \& Wray S 2012 Progesterone directly and rapidly inhibits GnRH neuronal activity via progesterone receptor membrane component 1. Endocrinology 153 4457-4469. (doi:10.1210/en.20121122)

Baynes SM \& Scott AP 1985 Seasonal variations in parameters of milt production and in plasma concentration of sex steroids of male rainbow trout (Salmo gairdneri). General and Comparative Endocrinology 57 150-160. (doi:10.1016/0016-6480(85)90211-4)

Belanger RM, Pachkowski MD \& Stacey NE 2010 Methyltestosteroneinduced changes in electro-olfactogram responses and courtship behaviors of cyprinids. Chemical Senses 35 65-74. (doi:10.1093/ chemse/bjp085)

Blaustein JD 1986 Steroid receptors and hormone action in the brain. Annals of the New York Academy of Sciences 474 400-414. (doi:10.1111/j.1749-6632.1986.tb28030.x)

Cermak T, Doyle EL, Christian M, Wang L, Zhang Y, Schmidt C, Baller JA, Somia NV, Bogdanove AJ \& Voytas DF 2011 Efficient design and assembly of custom TALEN and other TAL effector-based constructs for DNA targeting. Nucleic Acids Research 185 1-9.

Chen W \& Ge W 2012 Ontogenic expression profiles of gonadotropins ( $f s h b$ and $l h b$ ) and growth hormone $(g h)$ during sexual differentiation and puberty onset in female zebrafish. Biology of Reproduction 86 1-11.

Chen SX, Bogerd J, García-López Á, Jonge H, de Waal PP, Hong WS \& Schulz RW 2010 Molecular cloning and functional characterization of a zebrafish nuclear progesterone receptor. Biology of Reproduction $\mathbf{8 2}$ 171-181. (doi:10.1095/biolreprod.109.077644)

Chen SX, Bogerd J, Schoonen NE, Martijn J, de Waal PP \& Schulz RW 2013 A progestin $(17 \alpha, 20 \beta$-dihydroxy-4-pregnen-3-one) stimulates early stages of spermatogenesis in zebrafish. General and Comparative Endocrinology 185 1-9. (doi:10.1016/j.ygcen.2013.01.005)

Chu L, Li J, Liu Y, Hu W \& Cheng CH 2014 Targeted gene disruption in zebrafish reveals noncanonical functions of LH signaling in reproduction. Molecular Endocrinology 28 9292-9296.

Conneely OM, Sullivan WP, Toft DO, Birnbaumer M, Cook RG, Maxwell BL, Zarucki-Schulz T, Greene GL, Schrader WT \& O'Malley BW 1986 Molecular cloning of the chicken progesterone receptor. Science 233 767-770. (doi:10.1126/science.2426779)

Corbani M, Counis R, Wolinska-Witort E, d'Angelo-Bernard G, Moumni M \& Jutisz M 1990 Synergistic effects of progesterone and oestradiol on rat LH subunit mRNA. Journal of Molecular Endocrinology 4 119-125.

De Waal PP, Leal MC, García-López Á, Liarte S, de Jonge H, Hinfray N, Brion F, Schulz RW \& Bogerd J 2009 Oestrogen-induced androgen insufficiency results in a reduction of proliferation and differentiation of spermatogonia in the zebrafish testis. Journal of Endocrinology $\mathbf{2 0 2}$ 287-297. (doi:10.1677/JOE-09-0050)

Dulka JG, Stacey NE, Sorensen PW \& Vanderkraak GJ 1987 A steroid sex pheromone synchronizes male-female spawning readiness in goldfish. Nature 325 251-253. (doi:10.1038/325251a0)

Golan M, Martin AO, Mollard P \& Levavi-Sivan B 2016 Anatomical and functional gonadotrope networks in the teleost pituitary. Scientific Reports 6 23777. (doi:10.1038/srep23777)

Hanna RN \& Zhu Y 2009 Expression of membrane progestin receptors in zebrafish (Danio rerio) oocytes, testis and pituitary. General and Comparative Endocrinology 161 153-157. (doi:10.1016/j. ygcen.2008.10.006)

Hanna RN \& Zhu Y 2011 Controls of meiotic signaling by membrane or nuclear progestin receptor in zebrafish follicle-enclosed oocytes. Molecular and Cellular Endocrinology 337 80-88. (doi:10.1016/j. mce.2011.02.004)

Hanna RN, Daly SCJ, Pang Y, Anglade I, Kah O, Thomas P \& Zhu Y 2010 Characterization and expression of the nuclear progestin receptor in zebrafish gonads and brain. Biology of Reproduction 82 112-122. (doi:10.1095/biolreprod.109.078527)

Huang P, Xiao A, Zhou M, Zhu Z, Lin S \& Zhang BN 2011 Heritable gene targeting in zebrafish using customized TALENs. Nature Biotechnology 29 699-700. (doi:10.1038/nbt.1939)

Huggard-Nelson DL, Nathwani PS, Kermouni A \& Habibi HR 2002 Molecular characterization of LH- $\beta$ and FSH- $\beta$ subunits and their regulation by estrogen in the goldfish pituitary. Molecular and Cellular Endocrinology 188 171-193. (doi:10.1016/S0303-7207(01)00716-X)

Kerrigan JR, Dalkin AC, Haisenleder DJ, Yasin M \& Marshall JC 1993 Failure of gonadotropin-releasing hormone $(\mathrm{GnRH})$ pulses to increase luteinizing hormone beta messenger ribonucleic acid in GnRHdeficient female rats. Endocrinology 133 2071-2079.

Kobayashi M, Sohn YC, Yoshiur Y \& Aida K 2000 Effects of sex steroids on the mRNA levels of gonadotropin subunits in juvenile and ovariectomized goldfish Carassius auratus. Fisheries Science 66 223-231. (doi:10.1046/j.1444-2906.2000.00038.x)

Kobayashi M, Sorensen PW \& Stacey NE 2002 Hormonal and pheromonal control of spawning behavior in the goldfish. Fish Physiology Biochemistry 26 71-84. (doi:10.1023/A:1023375931734)

Levavi-Sivan B, Biran J \& Fireman E 2006 Sex steroids are involved in the regulation of gonadotropin-releasing hormone and dopamine D2 receptors in female tilapia pituitary. Biology of Reproduction $\mathbf{7 5}$ 642-650.

Lin SW \& Ge W 2009 Differential regulation of gonadotropins (FSH and $\mathrm{LH})$ and growth hormone (GH) by neuroendocrine, endocrine, and paracrine factors in the zebrafish - an in vitro approach. General and Comparative Endocrinology 160 183-193. 
Miura T, Yamauchi K, Takahashi H \& Nagahama Y 1992 The role of hormones in the acquisition of sperm motility in salmonid fish. Journal of Experimental Zoology 261 359-363. (doi:10.1002/ jez.1402610316)

Miura T, Higuchi M, Ozaki Y, Ohta T \& Miura C 2006 Progestin is an essential factor for the initiation of the meiosis in spermatogenetic cells of the eel. PNAS 103 7333-7338. (doi:10.1073/pnas.0508419103)

Nóbrega RH, Morais RD, Crespo D, de Waal PP, de Franca LR, Schulz RW \& Bogerd J 2015 Fsh stimulates spermatogonial proliferation and differentiation in zebrafish via Igf3. Endocrinology 156 3804-3817. (doi:10.1210/en.2015-1157)

O'byrne KT, Thalabard JC, Grosser PM, Wilson RC, Williams CL, Chen MD, Ladendorf D, Hotchkiss J \& Knobil E 1991 Radiotelemetric monitoring of hypothalamic gonadotropinreleasing hormone pulse generator activity throughout the menstrual cycle of the rhesus monkey. Endocrinology 1291207 1214. (doi:10.1210/endo-129-3-1207)

Park D, Kim C, Kim K \& Ryu K 1996 Progesterone together with estradiol promotes luteinizing hormone $\beta$-subunit mRNA stability in rat pituitary cells cultured in vitro. European Journal of Endocrinology 134 236-242. (doi:10.1530/eje.0.1340236)

Pawlowski S, Van Aerle R, Tyler CR \& Braunbeck T 2004 Effects of $17 \alpha$-ethinylestradiol in a fathead minnow (Pimephales promelas) gonadal recrudescence assay. Ecotoxicology and Environmental Safety $\mathbf{5 7}$ 330-345. (doi:10.1016/j.ecoenv.2003.07.019)

Schmittgen TD \& Livak KJ 2008 Analyzing real-time PCR data by the comparative CT method. Nature Protocol 3 1101-1108. (doi:10.1038/ nprot.2008.73)

Schneider JS, Burgess C, Sleiter NC, DonCarlos LL, Lydon JD \& O'Malley B 2005 Enhanced sexual behaviors and androgen receptor immunoreactivity in the male progesterone receptor knockout mouse. Endocrinology 146 4340-4348. (doi:10.1210/en.2005-0490)

Schulz RW, de França LR, Lareyre JJ, Gac FL, Garcia HC, Nobrega RH \& Miura T 2010 Spermatogenesis in fish. General and Comparative Endocrinology 165 390-411. (doi:10.1016/j.ygcen.2009.02.013)

Scott AP, Sumpter JP \& Stacey N 2010 The role of the maturationinducing steroid, 17, 20 $\beta$-dihydroxypregn-4-en-3-one, in male fishes: a review. Journal of Fish Biology 76 183-224.

Simard J, Labrie C, Hubert JF \& Labrie F 1988 Modulation by sex steroids and $\left[\mathrm{D}-\mathrm{TRP}^{6}\right.$,Des-Gly- $\left.\mathrm{NH}_{2}{ }^{10}\right]$ luteinizing hormone $(\mathrm{LH})$-releasing hormone ethylamide of $\alpha$-subunit and LH $\beta$ messenger ribonucleic acid levels in the rat anterior pituitary gland. Molecular Endocrinology 2 775-784. (doi:10.1210/mend-2-9-775)

Skaar KS, Nobrega RH, Magaraki A, Olsen LC, Schulz RW \& Male R 2011 Proteolytically activated, recombinant anti-Müllerian hormone inhibits androgen secretion, proliferation, and differentiation of spermatogonia in adult zebrafish testis organ cultures. Endocrinology 152 3527-3540. (doi:10.1210/en.2010-1469)

Skinner DC, Evans NP, Delaleu B, Goodman RL, Bouchard P \& Caraty A 1998 The negative feedback actions of progesterone on gonadotropinreleasing hormone secretion are transduced by the classical progesterone receptor. PNAS 95 10978-10983.

Sleiter N, Pang Y, Park C, Horton TH, Dong J, Thomas P \& Levine JE 2009 Progesterone receptor A (PRA) and PRB-independent effects of progesterone on gonadotropin-releasing hormone release. Endocrinology $1503833-3844$.

So WK, Kwok HF \& Ge W 2005 Zebrafish gonadotropins and their receptors: II. Cloning and characterization of zebrafish folliclestimulating hormone and luteinizing hormone subunits - their spatial-temporal expression patterns and receptor specificity. Biology of Reproduction 72 1382-1396. (doi:10.1095/biolreprod.104.038216)

Stacey NE \& Sorensen PW $198617 \alpha$, 20 $\beta$-dihydroxy-4-pregnen-3-one: a steroidal primer pheromone increasing milt volume in the goldfish, Carassius auratus. Canadian Journal of Zoology $642412-2417$. (doi:10.1139/z86-360)
Tan W \& Thomas P 2015 Involvement of epidermal growth factor receptors and mitogen-activated protein kinase in progestininduction of sperm hypermotility in Atlantic croaker through membrane progestinreceptor-alpha. Molecular and Cellular Endocrinology 414 194-201. (doi:10.1016/j.mce.2015.06.023)

Thackray VG, McGillivray SM \& Mellon PL 2006 Androgens, progestins, and glucocorticoids induce follicle-stimulating hormone $\beta$-subunit gene expression at the level of the gonadotrope. Molecular Endocrinology 20 2062-2079. (doi:10.1210/me.2005-0316)

Thackray VG, Hunnicutt JL, Memon AK, Ghochani Y \& Mellon PL 2009 Progesterone Inhibits basal and gonadotropin-releasing hormone induction of luteinizing hormone $\beta$-subunit gene expression. Endocrinology 150 2395-2403. (doi:10.1210/en.2008-1027)

Thomas P 2008 Characteristics of membrane progestin receptor alpha $(\mathrm{mPR} \alpha)$ and progesterone membrane receptor component 1 (PGMRC1) and their roles in mediating rapid progestin actions. Frontiers in Neuroendocrinology 29 292-312.

Tubbs C \& Thomas P 2008 Functional characteristics of membrane progestin receptor alpha $(\mathrm{mPR} \alpha)$ subtypes: a review with new data showing mPR $\alpha$ expression in seatrout sperm and its association with sperm motility. Steroids 73 935-941. (doi:10.1016/j.steroids.2007.12.022)

Turgeon JL \& Waring DW 1990 Rapid augmentation by progesterone of agonist-stimulated luteinizing hormone secretion by cultured pituitary cells. Endocrinology 127 773-780. (doi:10.1210/endo-1272-773)

Turgeon JL \& Waring DW 2000 Progesterone regulation of the progesterone receptor in rat gonadotropes 1. Endocrinology 141 3422-3429.

Turgeon JL, Kimura Y, Waring DW \& Mellon PL 1996 Steroid and pulsatile gonadotropin-releasing hormone $(\mathrm{GnRH})$ regulation of luteinizing hormone and GnRH receptor in a novel gonadotrope cell line. Molecular Endocrinology 10 439-450.

Ueda H, Kambegawa A \& Nagahama Y 1985 Involvement of gonadotrophin and steroid hormones in spermiation in the amago salmon, Oncorhynchus rhodurus, and goldfish, Carassius auratus. General and Comparative Endocrinology 59 24-30. (doi:10.1016/00166480(85)90415-0)

Van den Belt K, Berckmans P, Vangenechten C, Verheyen R \& Witters H 2004 Comparative study on the in vitro/in vivo estrogenic potencies of $17 \beta$-estradiol, estrone, $17 \alpha$-ethynylestradiol and nonylphenol. Aquatic Toxicology 66 183-195. (doi:10.1016/j.aquatox.2003.09.004)

Van der Kraak G 2009 The GnRH system and the neuroendocrine regulation of reproduction. Fish Physiology 28 115-149. (doi:10.1016/ S1546-5098(09)28003-4)

Van der Ven L, Wester PW \& Vos JG 2003 Histopathology as a tool for the evaluation of endocrine disruption in zebrafish (Danio rerio). Environmental Toxicology Chemistry 22 908-913. (doi:10.1897/15515028(2003)022<0908:HAATFT>2.0.CO;2)

Van der Ven L, Van den Brandhof EJ, Vos JH \& Wester PW 2007 Effects of the estrogen agonist $17 \beta$-estradiol and antagonist tamoxifen in a partial life-cycle assay with zebrafish (Danio rerio). Environmental Toxicology Chemistry 26 92-99. (doi:10.1897/06-092R1.1)

Waring DW \& Turgeon JL 1992 A pathway for luteinizing hormone releasing-hormone self-potentiation: cross-talk with the progesterone receptor. Endocrinology 130 3275-3282.

Westerfield M 2000 The Zebrafish Book: A Guide for the Laboratory Use of Zebrafish (Danio rerio). Eugene, OR, USA: University of Oregon Press.

Zhang Z, Lau SW, Zhang L \& Ge W 2015a Disruption of zebrafish folliclestimulating hormone receptor (fshr) but not luteinizing hormone receptor (lhcgr) gene by TALEN leads to failed follicle activation in females followed by sexual reversal to males. Endocrinology 156 3747-3762.

Zhang Z, Zhu B \& Ge W $2015 b$ Genetic analysis of zebrafish gonadotropin (FSH and LH) functions by TALEN-mediated gene disruption. Molecular Endocrinology 29 76-98. http://joe.endocrinology-journals.org

DOI: 10.1530/JOE-16-0073
(C) 2016 Society for Endocrinology Printed in Great Britain
Published by Bioscientifica Ltd. 
Zhu Y, Rice CD, Pang Y, Pace M \& Thomas P 2003 Cloning, expression, and characterization of a membrane progestin receptor and evidence it is an intermediary in meiotic maturation of fish oocytes. PNAS $\mathbf{1 0 0}$ 2231-2236. (doi:10.1073/pnas.0336132100)

Zhu Y, Hanna RN, Schaaf MJM, Spaink HP \& Thomas P 2008 Candidates for membrane progestin receptors - past approaches and future challenges. Comparative Biochemistry \& Physiology Part C: Toxicology \& Pharmacology 148 381-389.
Zhu Y, Liu D, Shaner ZC, Chen S, Hong W \& Stellwag EJ 2015 Nuclear progestin receptor (Pgr) knockouts in zebrafish demonstrate role for Pgr in ovulation but not in rapid nongenomic steroid mediated meiosis resumption. Frontiers in Endocrinology 637.

Zohar Y, Muñoz-Cueto JA, Elizur A \& Kah O 2010 Neuroendocrinology of reproduction in teleost fish. General and Comparative Endocrinology 165 438-455. (doi:10.1016/j.ygcen.2009.04.017)

Received in final form 13 April 2016

Accepted 22 April 2016

Accepted Preprint published online 25 April 2016
(C) 2016 Society for Endocrinology Printed in Great Britain
Published by Bioscientifica Ltd. 